\title{
Closure and rehabilitation detailed design for a tailings storage facility: case study of a gold mine in Quebec, Canada
}

I Ouchebri Golder, a member of WSP, Canada

A Göksu Golder, a member of WSP, Canada

F Junqueira Golder, a member of WSP, Canada

\begin{abstract}
The preservation of ecosystems surrounding mine sites and the rehabilitation of disturbed ecosystems due to mine activities is a key responsibility of mine operators. In Canada, federal and provincial regulations are established to control mining activities and assist mine operators in developing a successful management system for tailings facilities, through planning, construction, operation and closure. A Closure and Rehabilitation Plan has been prepared for an acid-generating tailings storage facility (TSF) in Quebec (Canada) as part of the mine's progressive reclamation effort and in order to meet regulatory closure requirements.

This article presents background information on the TSF, the main closure objectives and the rehabilitation strategy, concepts and design principles. Details for the rationale behind various choices made throughout the planning and design phases, as well as a description of the design, are presented with regards to the cover system and water management strategy.

Based on research conducted at the mine site, a 1.4-m thick cover with a capillary barrier effect (CCBE) has been designed to limit oxygen diffusion and water infiltration into the acid-generating tailings. The cover was designed to be constructed using materials available at or close to the site. Numerical simulations indicated that the proposed CCBE design could reduce surface water infiltration by $85 \%$ and significantly reduce oxygen diffusion into the mine tailings, thereby limiting acid generation and metal leaching in the long term. To validate design assumptions and monitor long-term performance of the cover and associated water management infrastructure, an instrumentation and monitoring plan was elaborated as part of the TSF closure plan, in compliance with mining Directive 019 (MELCC 2012) and the guidelines for preparing mine closure plans in Quebec (MERN 2017). This paper includes discussions on how the cover will be instrumented with moisture and temperature sensors, suction sensors and oxygen probes, as well as observation wells and surface water sampling stations.

The paper also presents the water management plan as an essential component of the reclamation and closure of the TSF. The water management plan aims to reproduce a hydrographic network, mimicking natural conditions: surface regrading will create topographic ridges and valleys, resulting in a stable "natural type" condition over the long term. Runoff water from the cover will flow over the surface of the TSF through engineered internal ditches built at the bottom of constructed valleys. These ditches extend into a discharge channel that will convey surface water runoff to the downstream natural watercourse. Water will only be released into the environment once water quality criteria are met. These water management structures are designed to create a robust system protecting the cover and dams from erosion in the long term. A new network of perimeter ditches and pumping stations was designed to collect and pump seepage and runoff water from around the TSF during the post-mining period. A staged construction schedule was also defined to minimize disturbance to the environment.
\end{abstract}

Keywords: rehabilitation, water management, cover system, tailings facility, closure, northern climate 


\section{Introduction}

Tailing Storage Facilities (TSF) present a mine-related risk to ecosystems and to human health in the vicinity, which is echoed in the high level of community concern regarding their operation, closure, rehabilitation and long-term care and maintenance. In the Province of Quebec (Canada), the Mining Act (2019) defines the relevant standards and local requirements that companies should apply to rehabilitate areas affected by their activities during both exploration and operation phases. The Act requires mine operators to submit a rehabilitation plan (referred to as "closure plan") and a financial guarantee covering the cost of the reclamation work. The plan must be approved by the Ministère de l'Énergie et des Ressources naturelles (MERN) before mining activities begin in the case of mineral exploration, and before a mining lease is issued in the case of mining operations. In both cases, the broad objective of the TSF rehabilitation plan strives to leave the affected area in a reliable and stable condition where little, if any, regular maintenance is needed. A closure and rehabilitation plan has been prepared for an acid-generating tailings storage facility in northern Quebec in order to meet standards, closure objectives and reclamation requirements for Quebec mine sites and as part of the progressive reclamation effort of the mine.

\section{Background}

The TSF was operated between 1981 and 1992 to store some 7 Mt of acid-generating tailings. It covers an area of approximately 80 hectares. Some of the waste rock produced by the mine was used for construction of roads, platforms and dike enhancements in and around the TSF. The waste rock and tailings were identified as acid-generating materials in the early stages of the operation. Hence, contact water was routed through a series of ditches and ponds to a high-density sludge water treatment plant.

Containment dikes up to $19 \mathrm{~m}$ in height have been constructed all around the TSF (Figure 1) and rest in several areas on loose deposits containing cohesive soils. Starter dikes made of till, sand, gravel and acid-generating waste rock were constructed around the TSF to contain the tailings. Subsequent dike raises were built with acid-generating waste rock using the upstream construction method to allow additional tailings containment.

The TSF is currently inactive. An internal pond collects runoff water from the TSF surface and is pumped to the TSF 1, which is an adjacent tailings storage facility currently in operation, for future treatment. The internal pond only collects the surface runoff from the TSF and is, as such, isolated from the remaining water management system of the site. Therefore, the TSF may be closed without affecting ongoing mining activities. The mine owner intends to phase out and rehabilitate the TSF over the next few years.

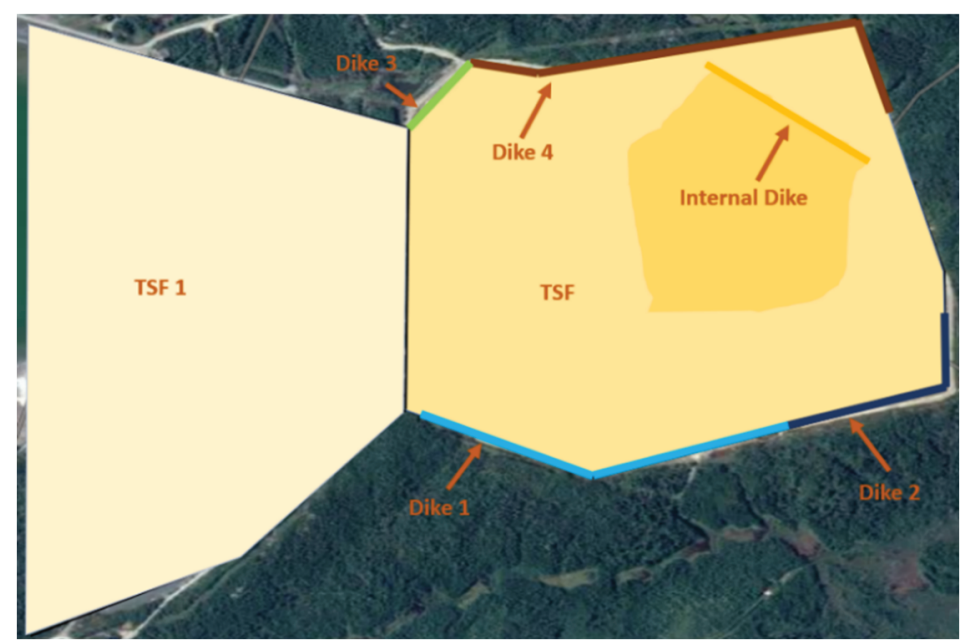

Figure 1 Studied TSF Closure Site 


\subsection{Closure Objectives}

Controlling the mine-related risk to public health and environment in the most durable fashion and preserving the acceptability of the mining industry in the communities where it operates are the focus of the mine decommissioning. Over time, contaminants can move from tailings through several processes, comprising air and waterborne transport or mass movements. Hence, the sources should be well identified, and the necessary precautions should be taken.

Specific objectives of the TSF closure plan are listed below:

- Limiting the infiltration of precipitation, snowmelt and the flow of oxygen to mine tailings, dikes and stability berms made of acid-generating materials in order to reduce the potential for sulphide oxidation leading to further acid generation and metal leaching that may affect the receiving environment;

- Redirecting runoff away from the footprint of the TSF and avoiding accumulation of water above mine tailings, dikes and stability berms;

- Building long-term stable structures from geotechnical and environmental standpoints to ensure long-term integrity of rehabilitation works;

- Ensuring the collection of temporarily contaminated water until the water quality improves and can be released into the environment according to the standards and closure criteria.

\subsection{Rehabilitation Strategies, Concepts and Design}

\subsubsection{Cover with Capillary Barrier Effect}

\subsubsection{Objectives}

A cover with capillary barrier effect (CCBE) will be used as a permanent surface barrier for the TSF closure. The cover is designed for northern climates and aims to limit the supply of oxygen and water to tailings and acid-generating waste rock (Aubertin et al., 2002; Mbonimpa et al., 2003; Bussière, 2007). More specifically, the objectives of the cover are to:

- Slow down the process of sulphide oxidation by limiting oxygen diffusion in the tailings and thus reducing the formation of acid mine drainage (AMD);

- Limit the infiltration of precipitation and snowmelt water in order to reduce the potential impacts associated with metal leaching as well as acid mine drainage;

- Prevent surface runoff from being in direct contact with tailings to facilitate the discharge of runoff without the need for treatment.

CCBEs have been used successfully at mine sites located in the region to limit oxygen diffusion and control the generation of AMD (e.g., Lorraine mine site - Dagenais et al. 2002, and Les Terrains Aurifères site Bussière et al. 2006).

\subsubsection{Strategies and Design}

The configuration of the cover is shown in Figure 2 and includes a basal layer of granular material creating a capillary barrier layer (CBL), covered by a compacted low-permeability moisture retention layer (MRL) composed of fine-grained soils. A granular protective layer (GPL) overlies the first two layers to support the growth of vegetation, prevent erosion, minimize desiccation of the moisture retention layer, and reduce the negative impacts of repetitive wetting, drying and freezing and thawing cycles on the low permeability layer. A nonwoven geotextile is incorporated at the interface of $C B L$ and MRL to prevent migration of fine soils in the coarser CBL that could compromise the design capillary break effect. The geotextile is permeable and has no hydraulic function in the cover configuration. 
The efficiency of the capillary barrier cover depends on the particle size, the water retention curves of the construction materials and the mine wastes (i.e., the ability of the materials to retain water in unsaturated conditions), as well as their saturated and unsaturated hydraulic conductivities (Aubertin et al. 2002). Borrow material characterization was performed to evaluate their hydrogeotechnical properties and design the CCBE. The oxygen flux from the surface of the cover to the tailings is strongly influenced by the degree of saturation of the MRL (Aachib et al. 2004). A significant reduction in oxygen diffusion through the cover will occur when the MRL sustains a degree of saturation of $85 \%$ or higher (Mbonimpa et al. 2003, GARD 2012).

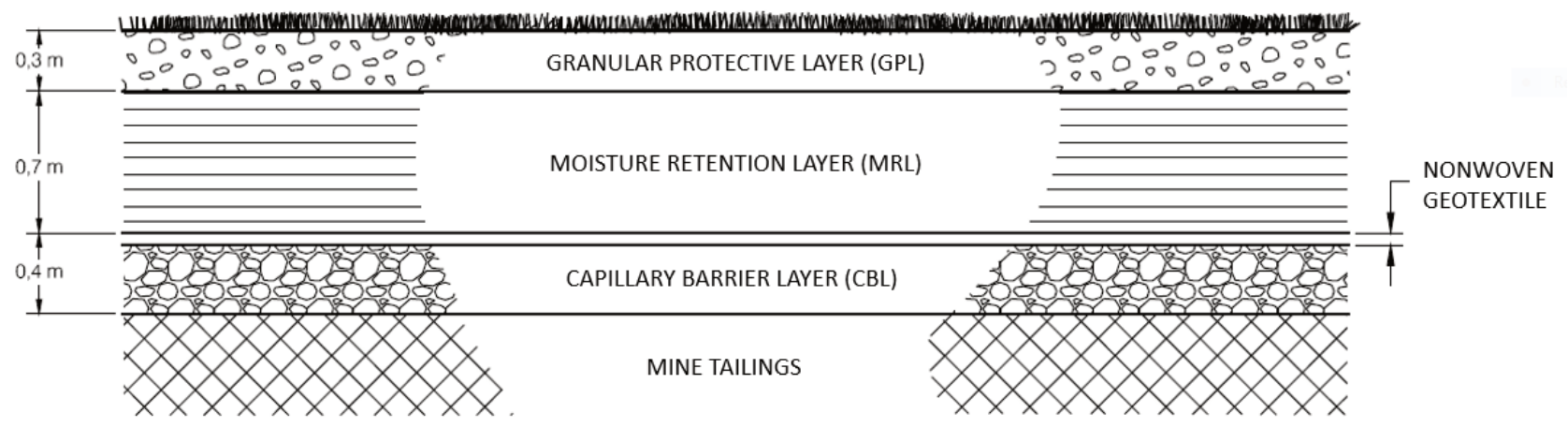

Figure 2 Configuration of Cover with Capillary Barrier Effect

The CCBE will be constructed on top of tailings and dams made of mine waste rock after regrading is completed. The CCBE construction will also extend to new stability berms and most existing roads made of acid-generating materials. The CCBE will be quickly vegetated once construction is completed in order to adequately protect the surface from wind and water erosion.

A subgrade layer will be prepared using NAG waste rock in places where soft tailings were identified. This will improve the trafficability in areas where the load bearing capacity of the materials is not sufficient to support construction equipment. This subgrade layer will further prevent upward migration of tailings into the basal granular layer of the cover, which would otherwise potentially compromise the capillary barrier effect. Moreover, the layer will be used for reprofiling TSF to promote surface runoff, as per the strategy described in a section below.

\subsubsection{Numerical Simulations}

Numerical simulations were carried out as part of this study to assess the potential performance of the CCBE and to predict temporal variations of the water table within the covered mine tailings. The numerical models were performed using one-dimensional (1D) and two-dimensional (2D) model configurations using the commonly used and well-known finite-element software SEEP/W, developed by GEO-SLOPE International. One-dimensional models, including several sensitivity analyses to assess the impact of changes in the material characteristics on the model results, were initially prepared for several scenarios to evaluate both rates of water percolation and oxygen diffusion to the tailings. Subsequently, $2 \mathrm{D}$ infiltration models were run for two cross-sections along the TSF. The water percolation rate through the cover computed in the 1D model was used as input in the 2D model to evaluate long-term variation in the position of the water table within the covered tailings. Simulation results indicated that a properly designed and constructed CCBE using available materials could reduce percolation of surface water at the base of the cover to 10 to $15 \%$ of the total annual precipitation for the long term and could significantly reduce oxygen diffusion into mine tailings, thereby ensuring satisfactory performance to meet the defined closure criteria. 


\subsubsection{Monitoring}

The CCBE will be instrumented with moisture/temperature sensors, suction/temperature sensors and oxygen probes to monitor its performance. Moisture and suction probes are used to help assess cover performance under saturated and unsaturated conditions, and oxygen probes are used directly to monitor variation in oxygen concentrations within and below the cover system. Vibrating wire piezometers and survey monuments will also be installed within the property boundaries, while observation wells and surface water sampling stations will be installed at the periphery to monitor overall closure performance. The monitoring program proposed as part of the closure plan of the TSF complies with provincial mining guidelines Directive 019 (MELCC 2012) and "Guide de preparation du plan de réaménagement et de restauration des sites miniers au Québec" (MERN 2017).

\subsubsection{Water Management}

\subsubsection{Objectives}

A natural surface topography will be recreated on the TSF cover: regrading will create topographic ridges and valleys, resulting in a stable natural landform over the long term. The most important objectives associated with the water management plan are:

- Collecting runoff and seepage water in accordance with the industry practice and current regulations to avoid unwanted discharge of contact water to the environment during the reclamation and post-reclamation phases;

- Protecting the cover systems from erosion, so it remains effective in the long term;

- Limiting water ponding on the cover by draining runoff efficiently and safely;

- Creating permanent internal structures with the appearance of a natural hydrographic network with the aim that the structures blend into the natural landform in the long term and have limited post-closure maintenance required.

A surface water management system will direct runoff from the tailings surface to the discharge channel through internal ditches. The ditches will be spaced to promote appropriate and effective surface drainage of the covered tailings area through engineered valleys. The ditches will merge into one main wider ditch that will become the discharge channel where it crosses the locally excavated dike. Further downstream, the discharge channel will be connected to an existing natural watercourse. Perimeter ditches, located at the toe of the tailings facility, will collect potential seepage and runoff water from the dikes' downstream slopes and direct them to pumping basins. All contact water will be pumped to TSF 1 (Figure 1) for treatment, until it meets the regulatory water quality criteria for discharge to the environment.

The overall cover and hydrography network are designed to allow safe overflow onto the tailings cover during extreme events (discussed below); i.e., no noticeable erosion would occur on the cover and within the designed ditches.

\subsubsection{Internal Ditches}

In order to meet the objective of recreating a natural landform in the interior of the TSF, a canal geometry mimicking natural rivers has been adopted, as part of the rehabilitation works. The natural hydrography is achieved by laying out channel geometries that are typical of alluvial streams. The internal ditches are designed with a cross-section made of a minor bed, a major bed and an extreme flood plain (Figure 3). 


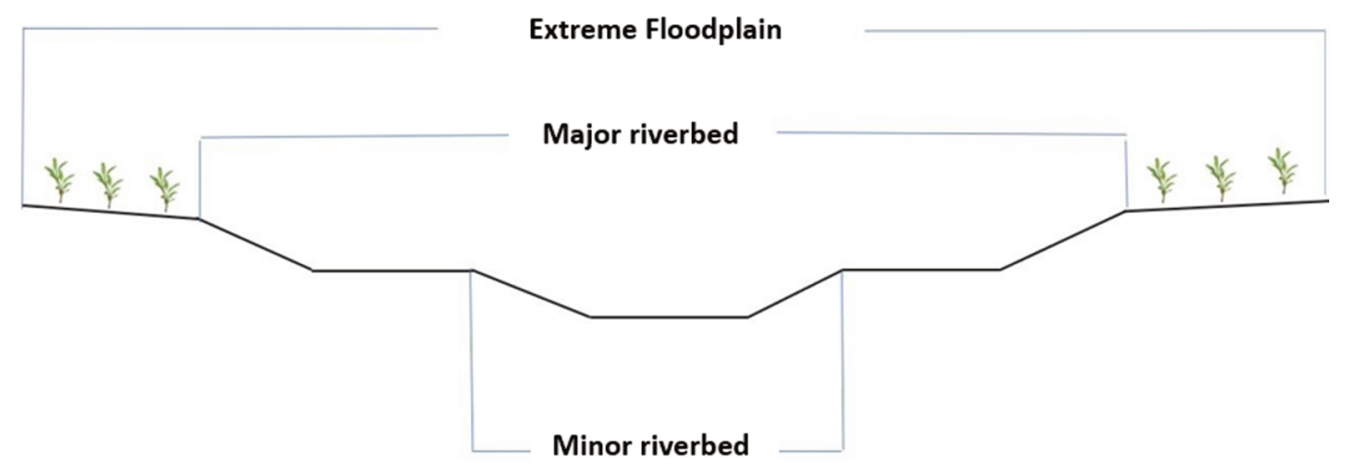

\section{Figure 3 Typical Section of an Internal Ditch}

Each of the zones composing the typical cross-section of the ditch is sized to pass a particular design flow, alike natural streams. A 2-year return period rainfall event is considered for the minor bed, a 100-year return period event is considered for the major bed, and the probable maximum precipitation (PMP) is adopted for the design of the extreme flood plain. The hydraulic capacity of each zone of the ditches is determined using Manning's equation (Smith, 1995).

All three zones of the ditches are designed so they will not erode during the PMP event. The characteristics of adequate erosion protection materials are calculated using the Simons and Sentürk (1977) method. Modelling resulted in the use of various types of erosion protection depending on the maximum flows and velocities that would transit through the different ditches sections and zones. Within the ditches minor beds, the calculation generally showed that coarse material or rip-rap armouring would be necessary for erosion protection. However, as for the overall tailings cover (outside the concentrated flow paths; i.e., the ditches), only revegetation is sufficient for erosion protection in upstream sections of the ditches. In these sections, a vegetation cover is determined to produce enough cohesive strength, while intermittent flow also allows for plant growth. Figure 4 showcase an example of a typical cross section of an internal ditch with the recommended erosion protection layers. As illustrated, only the upper layer material changes depending on the flow regime.

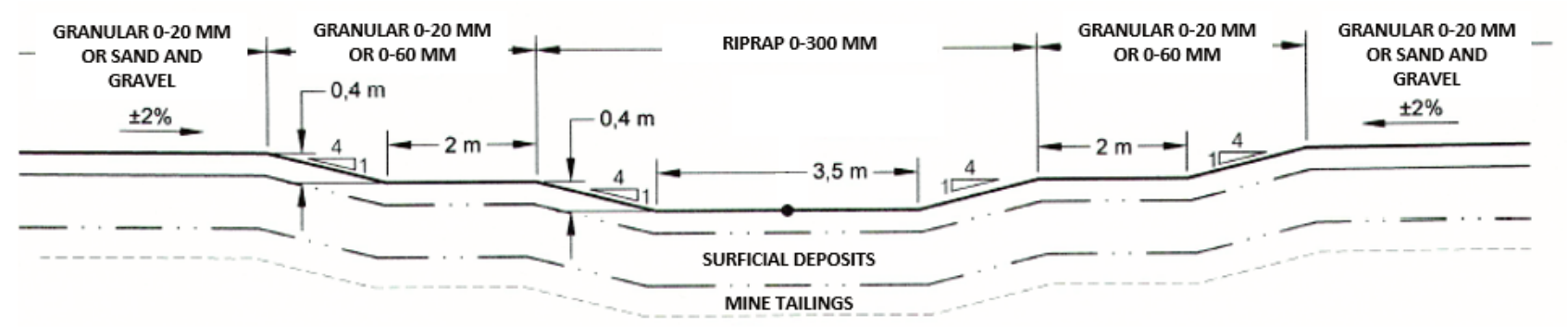

Figure 4 Typical Cross Section Erosion Protection Layers of an Internal Ditch

\subsubsection{Discharge Channel}

A Discharge channel will be built to convey surface water from the TSF to the natural watercourse downstream. The TSF's dike will be excavated locally to connect the internal ditches to the discharge channel. At te dike crossing, a trapezoidal channel cross section with lateral slopes of $4 \mathrm{H}: 1 \mathrm{~V}$ will be adopted. The discharge channel geometry will be adjusted to the conditions of the ground and existing topography. A twolevel natural geometry has been preferred to the three-level geometry used for the internal ditches. The reasoning for this is that the channel will have a steep gradient and will be excavated mostly in competent bedrock. This configuration will have typical hydraulic of a torrential stream for which no major bed is generally encountered. The discharge channel is designed to contain runoff from extreme events entirely within the minor bed.

A sedimentation basin is designed downstream of the discharge channel and prior to connection with the natural receiving watercourse. Upstream of the basin, the discharge channel is designed to safely route the 
PMP while limiting the risks of regressive erosion up to the TSF cover. Downstream of the basin, the discharge channel is designed to fully contain the 10-year return period rainfall event in the minor bed and to pass the 1000 -year return period rainfall event in the major bed without occurrence of significant erosion. Simulations were conducted using a Hydrologic Engineering Center's River Analysis System (HEC-RAS, 2017) model to estimate the hydraulic profiles for the different design events. Plotted results are presented in Figure 5.

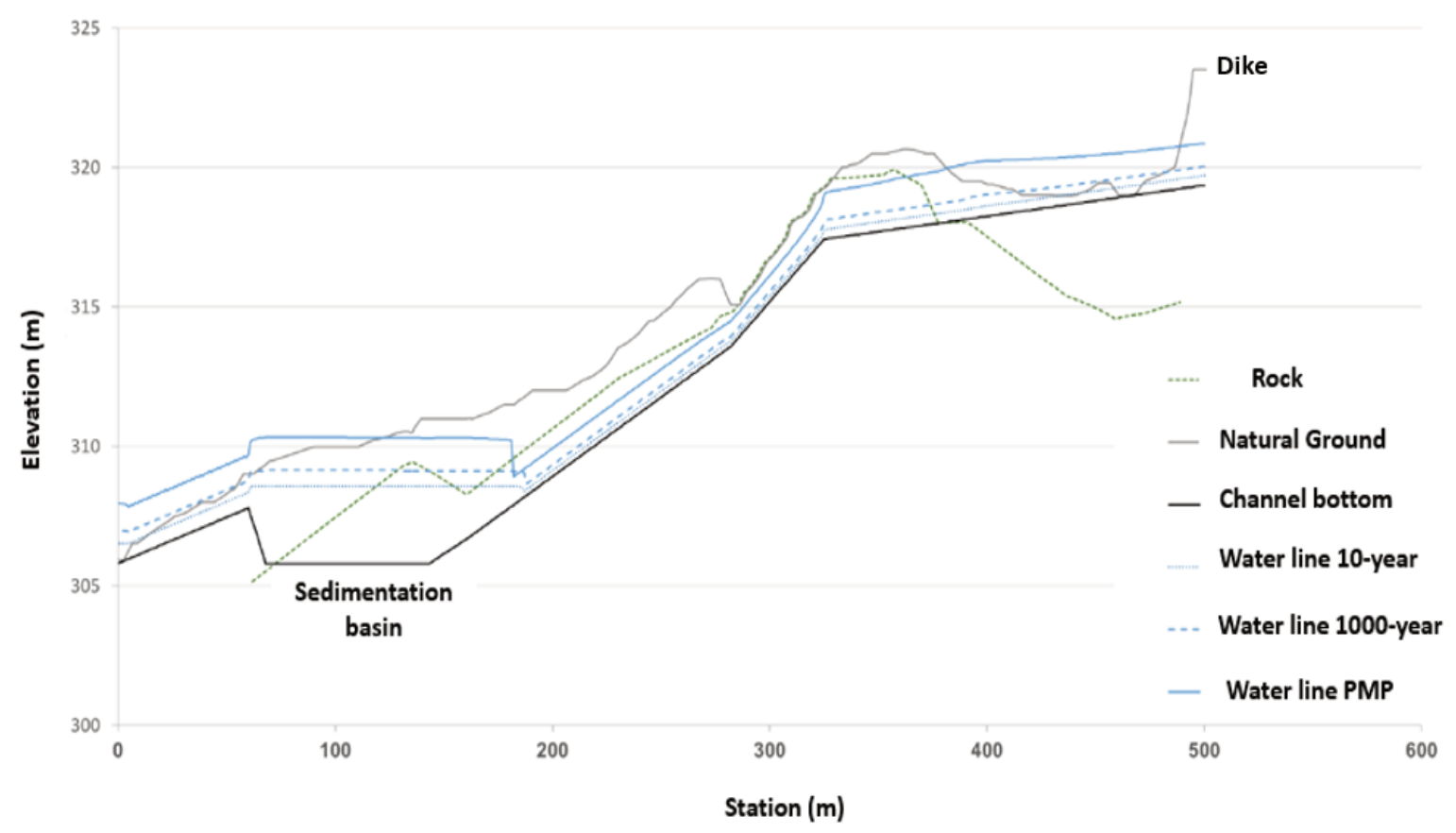

Figure 5 Hydraulic Profiles for Different Design Events in the Discharge Channel

\subsubsection{Sedimentation Basin}

The sedimentation basin is designed for scalable objectives achieved over time. It first acts as a sedimentation and pumping basin before being used as an energy dissipation basin. During the construction period of the discharge channel, the basin is used to decant suspended solids so that clean water can be discharged into the downstream watercourse. If the retained water does not meet the water quality criteria, it will be pumped to TSF 1 . In the post-reclamation period, once the water quality criteria are met, the sedimentation basin will no longer be necessary, and the pumping system will be discontinued. However, once the temporary berms and pumping basins within the TSF footprint are dismantled, the watershed reporting to the discharge channel and the associated discharge flow will increase. At this point, the sedimentation basin will become an energy dissipation basin. The basin is hence designed to fulfil both its pre- and postrestoration purposes.

\subsubsection{Perimeter Ditches}

Potential exfiltration and runoff water on the downstream slope of the TSF dikes will be collected by a new network of perimeter ditches and basins. Collected water will flow into basins 1 and 2 and will be pumped to TSF1 during the post-exploitation period (Figure 6).

The ditches have been designed to be able to contribute to the storage capacity of the basins when their water level is close to their maximum operating level. For the sections of the ditches contributing to the storage capacity, the water temporarily retained during a flood event represents a substantial risk of seepage to the environment. To limit this risk, the slope of the ditch adjacent to the environment is lined using either a geomembrane or a layer of low permeability soils, such as clay. The embankment of the ditch on the side of the tailings pond remains permeable to keep collecting seepage from the TSF. A 100-year return period 
rainfall event is considered for the design of the ditches and liner anchoring, in accordance with the Directive 019 (MELCC 2012). The water will be released directly into the environment once water quality criteria are met. A peripheral access road is integrated into the design to allow maintenance and monitoring of the various structures.

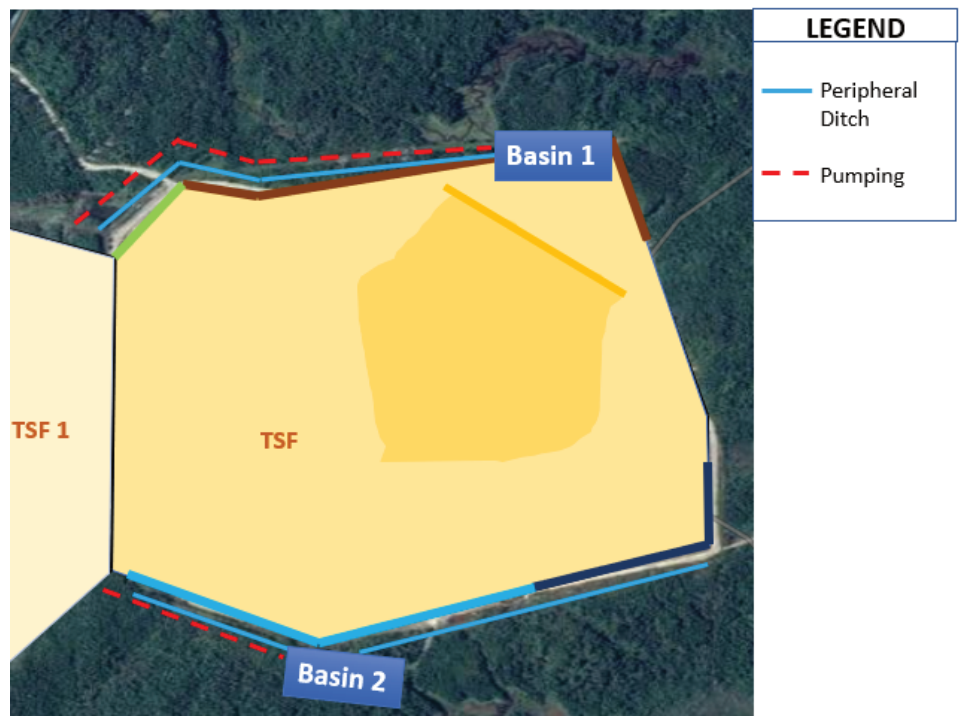

\section{Figure 6 Perimeter Ditches and Pumping Basins}

\subsubsection{Construction and Operation}

Construction of the cover and the internal ditches will be carried out in two main phases: post-mining and post-reclamation. During the post-mining period, the construction of the CCBE will allow a gradual isolation of tailings and other acid-generating materials. Runoff water will be collected in temporary pumping basins located in the upstream sector (PB1 to PB4) to facilitate the implementation of the cover and the ditches in the downstream sector of the TSF (Figure 7).

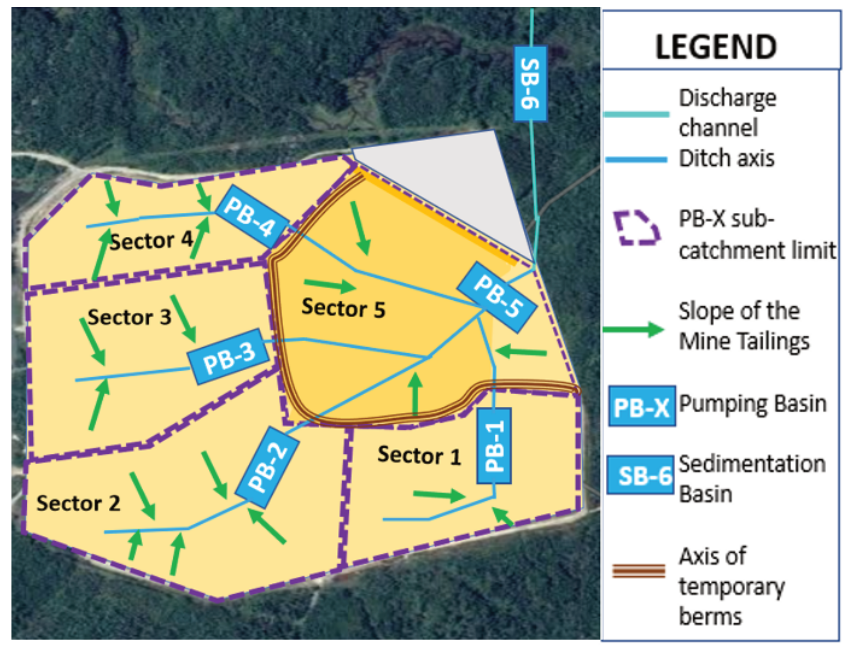

\section{Figure 7 Internal Drainage Network of the TSF in Post-Exploitation Phase}

During the post-reclamation period, all the temporary basins and berms (PB1 to PB5) will be used to retain runoff water until water quality standards are met. The water will be temporarily pumped to the tailings facility TSF 1 for future treatment. The temporary basins will be dismantled once the water quality meets the regulatory criteria for release into the environment, and the collected water will be discharged through the discharge channel previously described into the existing natural watercourse (Figure 8). 


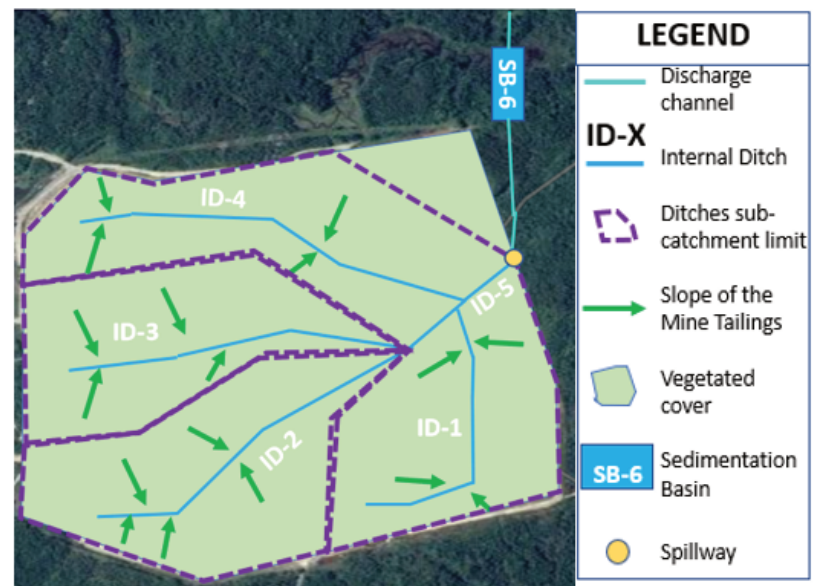

Figure 8 Internal Drainage Network of the TSF in Post-Reclamation Phase

\subsubsection{Tailings Surface Regrading}

The current TSF surface will be graded to limit potential erosion while allowing drainage to the TSF discharge channel. A slope of at least $0.5 \%$ on the tailings surface is planned for proper surface drainage and a maximum slope/maximum flow length of $2 \% / 200 \mathrm{~m}$ is adopted to avoid surface erosion, based on the Revised Universal Soil Loss Equation (RUSLE) (Wischmeier and Smith 1978; Renard et al. 1997). The tailings surface will be regraded to align with the four proposed internal ditch inverts (Figure 7). Excavated mine tailings will be used as a fill material elsewhere in the TSF, such that no tailings will be transported out of the TSF footprint.

All existing dikes will be reshaped at a maximum slope of $3 \mathrm{H}: 1 \mathrm{~V}$ in order to allow the construction of the proposed CCBE on their crest and lateral slopes. In addition, new stability buttresses will be needed in many places to attain long-term stability of dikes and their foundations. These stability berms will be constructed from acid-generating waste rock which will then be covered by the CCBE.

\subsubsection{Management of Contaminated Materials}

Anthropogenic activities in the TSF area may have contaminated the original ground surface. While most of the potentially contaminated material within the TSF footprint will be covered by the CCBE, structures around the TSF such as roads and existing embankments will not all be covered by the CCBE. It is believed that some of the structures around the TSF have been constructed with acid-generating waste rock. Outside the CCBE footprint, backfill materials will be characterized by determining their acid generation potential and their concentration in metals and metalloids. The geochemical characterization will be carried out as the restoration work progresses. If these materials are designated as potentially acid generating (PAG) or contaminated, they will be declared non-compliant and be reused as subgrade for the CCBE if their geotechnical properties allow it. Otherwise, they will be disposed of, in accordance with the regulation. The same procedures will be adopted for the natural soils of foundations located under PAG or contaminated embankments.

\subsubsection{Climate Change}

Climate change predictions indicate that significant differences must be expected between future climatic conditions and recent historical conditions. Taking these differences into account in the design of mining facilities is increasingly becoming an expected practice, particularly when planning for long-term closure measures. Numerous scientific publications present and discuss climate change forecasts. For Quebec, the Ouranos synthesis report (2015) is particularly relevant. It presents and analyses a whole range of predicted changes for four regions of Quebec. According to Mailhot et al. (2012), the consensus for the central Quebec region, where the mine site is located, is that extreme precipitation of all durations and all return periods will increase between $12 \%$ and $22 \%$. Therefore, a $20 \%$ increase in extreme storm event depth is accounted for in the design of the water management structures of the TSF described in the article. 


\section{Conclusion}

The maintenance of ecosystems neighbouring a mine site and the rehabilitation of closed mine sites are the responsibility of the mine operators. In this paper, the authors outline a case study presenting the rehabilitation strategies, concepts and design principles of a TSF closure in Quebec, Canada. Specifically, this article presents the capillary barrier cover system design and the water management plan to be implemented during the earthworks phase of decommissioning.

Since the late 90s, mine owners in the province of Quebec are obliged to prepare a closure plan in accordance with reclamation standards that have become more stringent in recent years. The closure plan described in this article was developed to meet the existing regulatory standards and to follow the most recent best practices targeting socially acceptable norms. With growing environmental awareness and strong interest in the mining industry and its social and environmental impacts, the authors emphasize the importance of encouraging all stakeholders to use a "cradle to grave" approach, integrating the closure planning early in mine projects and rethinking it regularly throughout the mine operations.

\section{Acknowledgement}

We would like to thank the Golder professional team for their constructive reviews, and in particular Vincent Martin, Anne-Marie Dagenais and Yves Boulianne for their support and review.

\section{References}

Aachib M, Mbonimpa M, Aubertin M 2004, 'Measurement and prediction of the oxygen diffusion coefficient in the unsaturated media, with applications to soil covers'. Water, Air and Soil Pollution, vol. 156, no. 1, pp.163-193.

Aubertin M, Bussière B, Bernier L 2002, 'Environnement et gestion des rejets miniers'. Les Presses Internationales de Polytechnique, Montréal, Québec, Canada.

Bussière B 2007, Colloquium 2004: 'Hydrogeotechnical properties of hard rock tailings from metal mines and emerging geoenvironmental disposal approaches'. Canadian Geotechnical Journal, vol. 44, no. 9, pp. 1019-1052. doi:10.1139/T07-040

Bussière B, Maqsoud A, Aubertin M, Martschuk J, McMullen J, Julien M 2006, 'Performance of the oxygen limiting cover at the LTA site, Malartic, Quebec'. CIM Bull, vol. 1, no. 6, pp. 1-11

Dagenais AM, Aubertin M, Bussière B, Cyr J, Fontaine R 2002, 'Auscultation et suivi du recouvrement multicouche construit au site minier Lorraine, Latulipe, Québec'. In Proceedings of Symposium sur l'Environnement et les Mines, Rouyn Noranda, Québec, Canada.

Guide, G.A.R.D. 2012, 'Global Acid Rock Drainage Guide. The International Network for Acid Prevention'. Available at: www. gardguide. com. Viewed 26 January 2021.

Mailhot A, Beauregard I, Talbot G, Caya D, Biner S 2012, 'Future changes in intense precipitation over Canada assessed from multimodel NARCCAP ensemble simulations'. International Journal of Climatology vol. 32, no. 8, pp. 1151-1163. doi :10.1002/joc.2343.

Mbonimpa M, Aubertin M, Aachib M, Bussière B 2003, 'Diffusion and consumption of oxygen in unsaturated cover materials'. Canadian Geotechnical Journal, vol. 40, no. 5, pp. 916-932.

MELCC 2012, Directive 019 sur l'industrie minière [in French]. Ministère de l'Environnement et de la Lutte contre les Changements Climatiques (MELCC) [known in 2012 as Ministère du Développement Durable, de l'Environnement et des Parc - MDDEP], Québec, Canada.

MERN 2017, Guidelines for preparing mine closure plans in Québec. Ministère de l'Énergie et des Ressources Naturelles du Québec (MERN), Québec, Canada.

Mining Act 2019, LégisQuébec official source. Chapitre M-13.1. http://legisquebec.gouv.qc.ca/en/ShowDoc/cs/M-13.1?langCont=en. Viewed 26 January 2021.

Ouranos 2015, 'Vers l'adaptation. Synthèse des connaissances sur les changements climatiques au Québec'. Édition 2015. Canada, Québec, Montréal.

Renard KG 1997, 'Predicting soil erosion by water: a guide to conservation planning with the Revised Universal Soil Loss Equation (RUSLE)'. United States Government Printing.

Simons DB \& Şentürk F 1977, 'Sediment transport technology: water and sediment dynamics'. Water Resources Publication.

Smith CD 1995, 'Hydraulic structures'. University of Saskatchewan Printing Services and Universal Bindery, Saskatoon, Sask.

USACE 2017, HEC-RAS River Analysis System - Applications Guide Version 5.0.7. United States Army Corps of Engineers (USACE), Hydrologic Engineering Center.

Wischmeier WH \& Smith DD 1978, 'Predicting rainfall erosion losses: a guide to conservation planning' (No. 537). United States Department of Agriculture, Science and Education Administration. 